Santa Clara University

Scholar Commons

Electrical Engineering

School of Engineering

$12-5-2005$

\title{
Structural Characteristics of Carbon Nanofibers for On-chip Interconnect Applications
}

Yusuke Ominami

Quoc Ngo

Alexander J.Austin

Hans Yoong

Cary Y. Yang

SantaClara University, cyang@scu.edu

See next page for additional authors

Follow this and additional works at: https://scholarcommons.scu.edu/elec

\section{Recommended Citation}

Y. Ominami, Q. Ngo, A.J. Austin, H. Yoong, C.Y. Yang, A.M. Cassell, B.A. Cruden, J. Li, and M. Meyyappan, "Structural Characteristics of Carbon Nanofibers for On-chip Interconnect Applications," Applied Physics Letters 87, 233105 (3 pp) (2005). https://doi.org/ $10.1063 / 1.2137873$

Copyright () 2005 American Institute of Physics Publishing. Reprinted with permission.

This Article is brought to you for free and open access by the School of Engineering at Scholar Commons. It has been accepted for inclusion in

Electrical Engineering by an authorized administrator of Scholar Commons. For more information, please contact rscroggin@scu.edu. 
Authors

Yusuke Ominami, Quoc Ngo, Alexander J. Austin, Hans Yoong, Cary Y. Yang, Alan M. Cassell, Brett A. Cruden, Jun Li, and M. Meyyappan 


\title{
Structural characteristics of carbon nanofibers for on-chip interconnect applications
}

\author{
Yusuke Ominami, ${ }^{\text {a) }}$ Quoc Ngo, Alexander J. Austin, Hans Yoong, and Cary Y. Yang \\ Center for Nanostructures, Santa Clara University, 500 El Camino Real, Santa Clara, California 95139
}

Alan M. Cassell, Brett A. Cruden, Jun Li, and M. Meyyappan

NASA Ames Research Center, Center for Nanotechnology, Moffett Field, California 94035

(Received 31 May 2005; accepted 4 October 2005; published online 29 November 2005)

\begin{abstract}
In this letter, we compare the structures of plasma-enhanced chemical vapor deposition of $\mathrm{Ni}$-catalyzed and Pd-catalyzed carbon nanofibers (CNFs) synthesized for on-chip interconnect applications with scanning transmission electron microscopy (STEM). The Ni-catalyzed CNF has a conventional fiberlike structure and many graphitic layers that are almost parallel to the substrate at the CNF base. In contrast, the Pd-catalyzed CNF has a multiwall nanotubelike structure on the sidewall spanning the entire CNF. The microstructure observed in the Pd-catalyzed fibers at the CNF-metal interface has the potential to lower contact resistance significantly, as our electrical measurements using current-sensing atomic force microscopy indicate. A structural model is presented based on STEM image analysis. (C) 2005 American Institute of Physics.
\end{abstract}

[DOI: $10.1063 / 1.2137873$ ]

The superior properties of carbon nanotubes (CNTs) and carbon nanofibers (CNFs) have given rise to an abundance of studies on potential applications. Nanoelectronic devices fabricated using these carbon-based nanostructures have been introduced for both transistor and interconnect applications. ${ }^{1,2}$ For interconnect applications, the resistance of carbon nanostructures and the carbon-substrate interface must be minimized. Resistance is closely tied to the CNF structure as determined by different growth methods ${ }^{3-5}$ or processes. ${ }^{6-9}$ Therefore low-resistance interconnect development using CNFs requires an understanding of the structure and critical feedback to the manufacturing process from high-resolution microscopy.

Previous studies have demonstrated the use of Pd as a near-ohmic contact material for a CNT device, ${ }^{10}$ and plasmaenhanced chemical vapor deposition (PECVD) of CNFs has also been demonstrated using a thin-film Pd catalyst. ${ }^{11-13}$ Our present work combines these two efforts using Pd as a catalyst material for growing vertically aligned CNF structures while minimizing structural disorder at the CNFcontact metal interface that can lead to high contact resistance. In this letter, we compare the structure of nanofibers catalyzed by $\mathrm{Ni}$ and Pd using scanning transmission electron microscopy (STEM). We also discuss which catalyst material is more suitable for interconnect development through analysis of the STEM images and electrical measurements.

We have previously proposed a "bottom-up" approach for developing CNF interconnects. ${ }^{14}$ The detailed conditions for PECVD of CNFs have been previously discussed. ${ }^{14-16} \mathrm{~A}$ $35 \mathrm{~nm}$ film of catalyst material ( $\mathrm{Ni}$ or $\mathrm{Pd}$ ) is deposited on either a $\mathrm{Cr}$ or $\mathrm{Pt}$ underlayer by electron-beam evaporation. CNFs are subsequently deposited using PECVD. ${ }^{15}$ In order to prepare a STEM sample for characterizing the body of the nanofiber, as-grown CNFs are dispersed in isopropyl alcohol, sonicated, and placed onto a copper grid coated with a lacey carbon film. For characterizing the CNF-metal interface re-

\footnotetext{
${ }^{\text {a)} E l e c t r o n i c ~ m a i l: ~ y o m i n a m i @ s c u . e d u ~}$
}

gion, CNFs are left attached to the substrate and $\mathrm{SiO}_{2}$ is deposited using tetraethoxysilane tetraethylorthosilicate chemical vapor deposition to encapsulate the as-grown nanofibers. ${ }^{14}$ The deposited $\mathrm{SiO}_{2}$ protects the CNF from damage during STEM sample preparation. The crosssectional STEM sample is then prepared using focused ion beam (FIB) thinning. In order to maintain the integrity of CNFs during sample preparation, sputtering using a $10 \mathrm{kV}$ FIB is used to prepare the STEM sample. The samples are imaged using a STEM with a point-to-point resolution of $0.204 \mathrm{~nm}$, equipped with energy-dispersive $\mathrm{x}$-ray spectroscopy (EDX) capability.

Low-magnification STEM images of Ni-catalyzed CNFs reveal a conventional fiberlike structure. ${ }^{6,17-19}$ At the tip section, a cup-shaped structure is observed and the structural transition of a cup-shaped angle from the tip to the bottom of the CNF is also observed as previously reported. ${ }^{7,18}$ Highresolution STEM observations show that the carbon structures comprising the cup-shape are graphitic layers with 0.34 nm spacing [Figs. 1(b)-1(f)]. The graphitic layer structure at the tip of a Ni-catalyzed PECVD nanofiber has been investigated by transmission electron microscopy previously, ${ }^{20}$ thus the discussion here will focus on the CNF body and interface nanostructure. Graphitic layers, approximately 5 $\mathrm{nm}$ in thickness, are observed along the sidewall as shown in Fig. 1(b). However, almost all of these graphitic layers become cup shaped toward the base of the nanofiber [Figs. 1(b) and 1(c)], with the bottom of each cup almost perpendicular to the nanofiber axis [Fig. 1(d)]. The types of disorders seen in Figs. 1(a)-1(c) are primarily responsible for the commonly observed inferior electrical properties of CNFs compared to ideal multiwalled (MW) carbon nanotubes, where all of the walls, end-to-end, are parallel to the central axis of the nanotube. A cross section of the CNF-substrate interface is shown in Figs. 1(e) and 1(f). The boundary among CNF, $\mathrm{SiO}_{2}$, and metal layer in the cross-sectional region is determined using EDX analysis. The structure of the CNFsubstrate interface encapsulated in $\mathrm{SiO}_{2}$ consists of many 

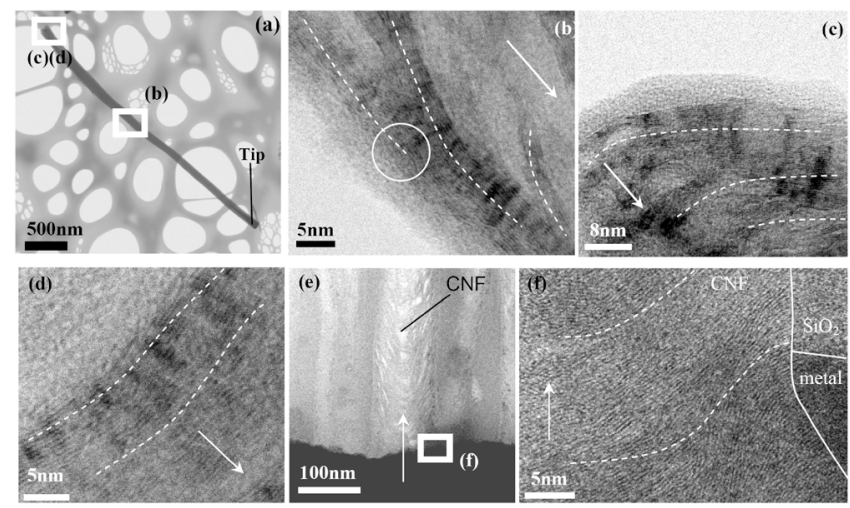

FIG. 1. STEM images illustrating the structure of a Ni-catalyzed CNF. (a) The view of an entire CNF and the high-resolution view of different sections of a CNF: (b) Sidewall, (c) in proximity of the base, and the (d) the center near the CNF base. (e) and (f) Cross-sectional views of the CNF-metal interface deposited in $\mathrm{SiO}_{2}$. In (b), the white circle shows the area where graphitic layers terminate. In (f), the solid line indicates the boundary between $\mathrm{CNF}$ and $\mathrm{SiO}_{2}$, which is determined using EDX analysis. The broken lines show the orientations of the graphitic layers. The solid arrows indicate the direction toward the CNF tip.

graphitic layers that are almost parallel to the substrate, as seen in Fig. 1(f).

STEM images of Pd-catalyzed CNFs at low magnification are shown in Fig. 2(a). Pd-catalyzed CNFs at the tip section have MW-like structures as shown in Fig. 2(b). The observation of Pd-catalyzed CNFs using high-resolution STEM reveals that the cup-shaped layers on the interior terminate to MW-like structures near the sidewall of the fiber, as shown in Figs. 2(c) and 2(d). Moreover, the striking characteristic of this Pd-catalyzed CNF is that the MW-like structures are observed not only at the tip section but also throughout and near the base of the nanofiber [Fig. 2(e)]. The thickness of the MW-like structure, shown in Figs. 2(d) and 2(e), is approximately $20 \mathrm{~nm}$. In addition, there is no cupshaped structure observed near the CNF base. STEM images exploring the fiber-metal interface area of the Pd-catalyzed CNF sample (prepared by FIB) are shown in Fig. 3. The interfacial structure of Pd-catalyzed CNFs shows MW-like morphology approaching the CNF-substrate interface that is almost perpendicular to the substrate. The cup-shaped struc-

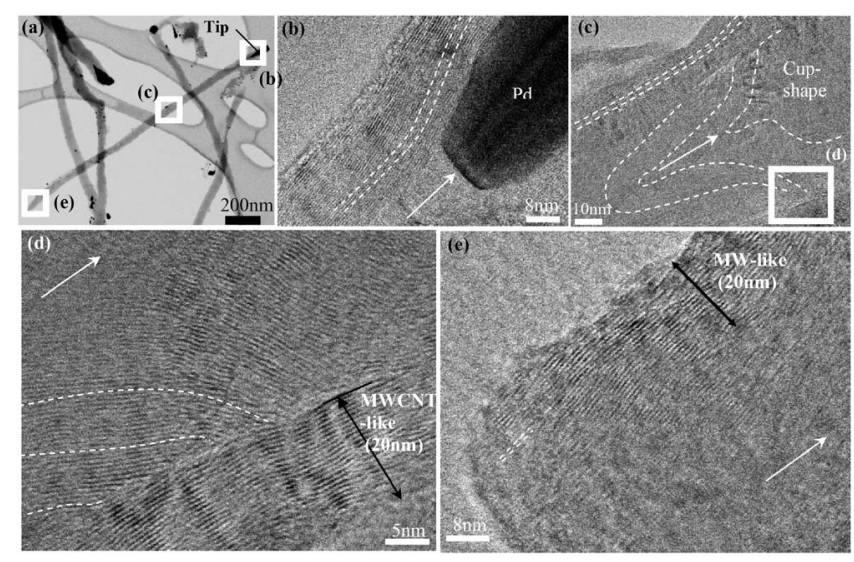

FIG. 2. STEM image of a Pd-catalyzed CNF (a) at low magnification. High-magnification images at the (b) tip and (c) center of the CNF. (d) The high magnification of (c). (e) The structure around CNF base. The white solid arrows indicate the direction toward the CNF tip. The broken lines indicate the graphitic layers' orientations.
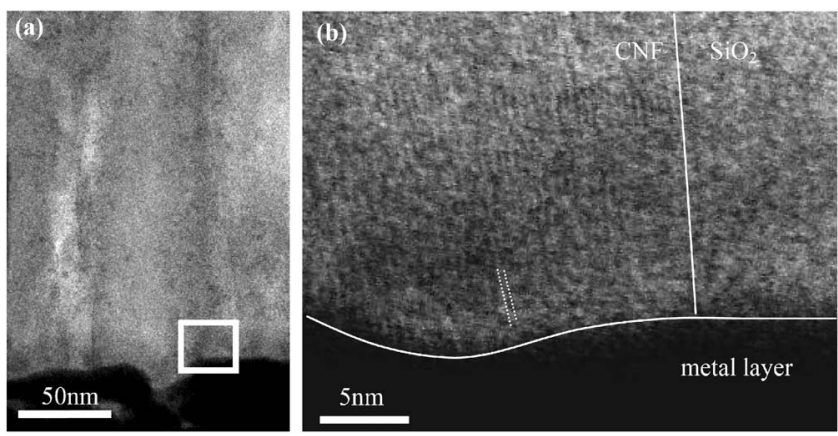

FIG. 3. STEM images of a Pd-catalyzed CNF at the base (a) at low magnification and (b) at high magnification. In (b), the solid lines indicate the boundary among $\mathrm{CNF}, \mathrm{SiO}_{2}$, and metal layer, which is determined by using EDX analysis. The broken lines indicate the graphitic layer orientations.

ture near the interface [Fig. 1(f)] is not observed, while it is present in the case of Ni-catalyzed fibers.

Current-voltage measurements show a reduction in resistance in the Pd-catalyzed CNFs when compared to Nicatalyzed CNFs. ${ }^{21}$ Current-sensing atomic force microscopy measurements of single nanofibers were conducted using the metal underlayer as bottom contact, and making top contact to the CNF through a conducting atomic force microscope probe tip. The choice of metal underlayers is inconsequential because measured sheet resistances of both $\mathrm{Cr}$ and $\mathrm{Pt}$ prior to PECVD showed just a few ohms, which is negligible in comparison to CNF resistance values measured in the $\mathrm{k} \Omega$ range. The resistance of a typical single Pd-catalyzed CNF measured using this configuration was around $9 \mathrm{k} \Omega$, with a distribution mean and standard deviation of $9.0 \pm 1.6 \mathrm{k} \Omega$. A typical Ni-catalyzed CNFs showed consistently higher resistances around $13 \mathrm{k} \Omega$, with a distribution mean and standard deviation of $13.3 \pm 3.0 \mathrm{k} \Omega{ }^{21}$ Further analysis of the resistance data using the Student's T distribution shows that the $\mathrm{Ni}$ - and Pd-catalyzed resistance distributions will not overlap at a $99 \%$ confidence level. Because the length $(4 \mu \mathrm{m})$ and diameter $(50 \mathrm{~nm})$ of these CNFs are similar, this difference in resistance can be attributed to structural differences between the two types of CNFs. These measurements include both tip-to-CNF and CNF-metal contact resistances and the systematic error inherent to the instrument. Nevertheless, the results demonstrate a difference in resistance between the two systems.

Figure 4 shows the proposed structural models of $\mathrm{Ni}$ catalyzed and Pd-catalyzed CNFs. In the case of a Nicatalyzed CNF, some graphitic layers may initially form under the Ni catalyst particle and the cup-shaped structure emerges as the growth continues. ${ }^{7}$ For interconnects, the cupshaped structure and arrangement of graphitic layers parallel to the substrate at the CNF base give rise to a significant resistance, as electrons must flow across the basal planes of the graphitic layers. In contrast, Pd-catalyzed CNFs have a MW-like structure on the sidewall from tip to bottom. In addition, the thickness of graphitic layers of Pd-catalyzed CNFs $(20 \mathrm{~nm})$ at the sidewall is larger than that of Nicatalyzed CNFs $(5 \mathrm{~nm})$. These structures are expected to facilitate better electron conduction as compared to $\mathrm{Ni}$ catalyzed CNFs, as electrons flow parallel to the nanofiber axis. It is likely that the difference in structure observed near the CNF-substrate interface is caused by dissimilar diffusion mechanisms of carbon atoms through different catalyst materials. It has been reported that carbon diffuses through a $\mathrm{Ni}$ 


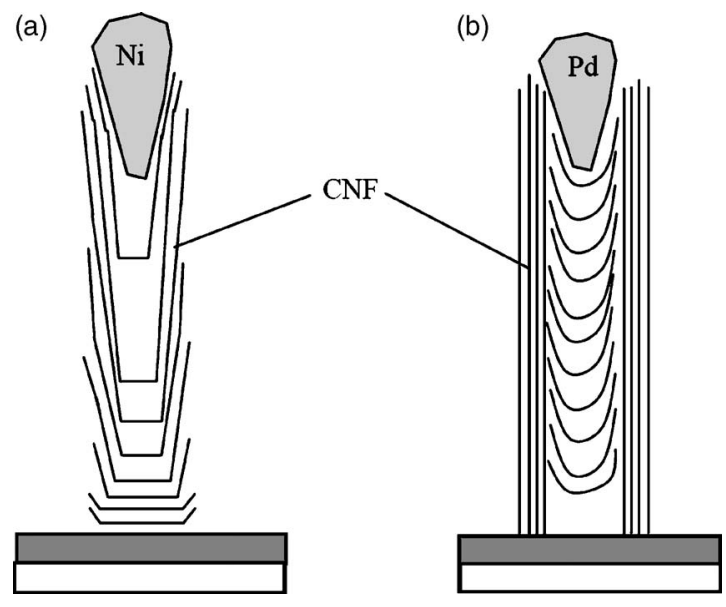

FIG. 4. The proposed structural model of (a) Ni-catalyzed CNF and (b) Pd-catalyzed CNF.

particle well during the PECVD of CNFs. ${ }^{8}$ As carbon atoms diffuse through the Ni particle, graphitic layers are created on the surface of the Ni particle. ${ }^{7}$ In the case of a Pd particle, rapid carbon diffusion ${ }^{22}$ may form graphitic layers on the outer edges of the particle parallel to the tube axis. The main difference in these two carbon diffusion mechanisms is the lack of graphitic layers being created underneath the Pd particle. As a result, during the initial growth of Pd-catalyzed CNFs, graphite layers are created on the sidewall of the Pd particle. More studies of carbon diffusion during PECVD using a Pd catalyst should be performed to gain a firm understanding of how the growth kinetics affect electrical properties of plasma-grown CNFs.

In summary, the interface and interior structures of Nicatalyzed and Pd-catalyzed CNFs are revealed using STEM. While Ni-catalyzed CNFs have a conventional fiberlike structure and stacked graphitic layers almost parallel to the substrate near the CNF-metal interface, Pd-catalyzed CNFs have a MW-like structure near the sidewall spanning the entire CNF, which, among other factors, leads to lower resistance for on-chip interconnect applications. The results suggest that $\mathrm{Pd}$ is a more suitable catalyst than $\mathrm{Ni}$ for the growth of CNFs used as on-chip interconnects.
The authors are grateful to Kevin Mcilwrath of Hitachi High-Technologies America for his expert assistance in FIB (FB-2100) and STEM (HD-2300) experiments.

${ }^{1}$ R. Martel, T. Schmidt, H. R. Shea, T. Hertel, and P. Avouris, Appl. Phys. Lett. 73, 2447 (1998).

${ }^{2}$ F. Kreupl, A. P. Graham, G. S. Duesberg, W. Steinhogl, M. Liebau, U. Unger, and W. Honlein, Microelectron. Eng. 64, 399 (2002).

${ }^{3}$ H. Cui, O. Zhou, and B. R. Stoner, J. Appl. Phys. 88, 6072 (2000).

${ }^{4}$ H. Ye, N. Naguib, Y. Gogotsi, G. Yazicioglu, and C. M. Megaridis, Nanotechnology 15, 232 (2004).

${ }^{5}$ M. Endo, Y. A. Kim, T. Hayashi, Y. Fukai, K. Oshida, M. Terrones, T. Yanagisawa, S. Higaki, and M. S. Dresselhaus, Appl. Phys. Lett. 80, 1267 (2002).

${ }^{6}$ V. I. Merkulov, M. A. Guillorn, D. H. Lowndes, and M. L. Simpson, Appl. Phys. Lett. 79, 1178 (2001).

${ }^{7}$ H. Cui, X. Yang, M. Simpson, D. Lowndes, and M. Varela, Appl. Phys. Lett. 84, 4077 (2004).

${ }^{8}$ S. Helveg, C. Lopez-Cartes, J. Shested, P. L. Hansen, B. S. Clausen, J. R. Rostrup-Nielson, F. Abild-Pederson, and J. K. Norskov, Nature (London) 427, 426 (2004).

${ }^{9}$ S. Tsai, C. Shiu. S. Lai, and H. Shih, Carbon 40, 1597 (2002).

${ }^{10}$ A. Javey, J. Guo, Q. Wang, M. Lundstrom, and H. Dai, Nature (London) 424, 654 (2003).

${ }^{11}$ L. H. Chang, K. H. Hong, S. H. Lai, X. W. Liu, and H. C. Shih, Thin Solid Films 423, 27 (2003).

${ }^{12}$ Y. M. Wong, W. P. Kang, J. L. Davidson, A. Wisitora-at, K. L. Soh, T. Fisher, Q. Li, and J. F. Xu, J. Vac. Sci. Technol. A 21, 391 (2003).

${ }^{13}$ S. Kita, Y. Sakai, T. Fukushima, Y. Mizuta, A. Ogawa, S. Senda, and F. Okuyama, Appl. Phys. Lett. 85, 4478 (2004).

${ }^{14}$ J. Li, Q. Ye, A. Cassell, H. T. Ng, R. Stevens, J. Han, and M. Meyyappan, Appl. Phys. Lett. 82, 2491 (2003).

${ }^{15}$ B. A. Cruden, A. M. Cassell, Q. Ye, and M. Meyyappan, J. Appl. Phys. 94, 4070 (2003).

${ }^{16}$ Q. Ngo, D. Petranovic, S. Krishnan, A. M. Cassell, Q. Ye, J. Li, M. Meyyappan, and C. Y. Yang IEEE Trans. Nanotechnol. 3, 311 (2004).

${ }^{17}$ L. Zhang, D. Austin, V. I. Merkulov, A. V. Meleshko, K. L. Klein, M. A. Guillorn, D. H. Lowndes, and M. L. Simpson, Appl. Phys. Lett. 84, 3972 (2004).

${ }^{18}$ J. B. O. Caughman, L. R. Baylor, M. A. Guillorn, V. I. Merkulov, D. H. Lowndes, and L. F. Allard, Appl. Phys. Lett. 83, 1207 (2003).

${ }^{19}$ L. Delzeit, I. McAninch, B. A. Cruden, D. Hash, B. Chen, J. Han, and M. Meyyappan, J. Appl. Phys. 91, 6027 (2002).

${ }^{20}$ J. G. Wen, Z. P. Huang, D. Z. Wang, J. H. Chen, S. X. Yang, Z. F. Ren, J. H. Wang, L. E. Calvet, J. Chen, J. F. Klemic, and M. A. Reed, J. Mater. Chem. 16, 3246 (2001).

${ }^{21}$ Q. Ngo, A. M. Cassell, A. J. Austin, J. Li, S. Krishnan, M. Meyyappan, and C. Y. Yang, IEEE Electron Device Lett. (2005) (submitted).

${ }^{22}$ H. Yokoyama, H. Numakura, and M. Koiwa, Acta Mater. 46, 2823 (1998). 